Article

\title{
Processes Underlying 50 Years of Local Forest-Cover Change in Yunnan, China
}

\author{
Jens Frayer ${ }^{1}$, Daniel Müller ${ }^{1,2, *}$, Zhanli Sun ${ }^{1}$, Darla K. Munroe ${ }^{3}$ and Jianchu Xu ${ }^{4}$ \\ 1 Leibniz Institute of Agricultural Development in Transition Economies (IAMO), \\ Theodor-Lieser-Str. 2, Halle (Saale) 06120, Germany; E-Mails: frayer@iamo.de (J.F.); \\ sun@iamo.de (Z.L.S.) \\ 2 Geography Department, Humboldt-Universität zu Berlin, Unter den Linden 6, \\ Berlin 10099, Germany \\ 3 Department of Geography, Ohio State University, 1036 Derby Hall, 154 N. Oval Mall, \\ Columbus, OH 43210, USA; E-Mail: munroe.9@osu.edu \\ 4 World Agroforestry Centre, East Asia Node, Lanhei Road 132\#, Heilongtan, \\ Kunming 650201, Yunnan, China; E-Mail: J.C.Xu@cgiar.org \\ * Author to whom correspondence should be addressed; E-Mail: mueller@iamo.de; \\ Tel.: +49-0345-2928328; Fax: +49-0345-2928399.
}

External Editor: Eric J. Jokela

Received: 25 September 2014; in revised form: 5 December 2014 / Accepted: 11 December 2014 / Published: 16 December 2014

Abstract: Recognition of the importance of forests for local livelihoods, biodiversity and
the climate system has spurred a growing interest in understanding the factors that drive
forest-cover change. Forest transitions, the change from net deforestation to net
reforestation, may follow different pathways depending on a complex interplay of driving
forces. However, most studies on forest transitions focus on the national level rather than
the local level. Here, case studies from 10 villages in Yunnan, China, are used to clarify the
complex interactions among various pathways of forest transitions, derive insights on the
underlying drivers that shaped the forest transitions, and determine the importance of
changes in drivers over time. The results demonstrate that China's recent forest transition was
caused by a range of interrelated pathways that were mediated by local circumstances. The
degradation of forest ecosystem services caused by rampant deforestation and forest
degradation created a scarcity of forest products and triggered state-initiated afforestation
efforts, particularly in the 1990s, which continue to be important. More recently, economic 
development concomitant with smallholder intensification spurred reforestation, while the importance of state forest policy declined. The complexity of local land-use changes demonstrates the difficulty of identifying distinct transition pathways and calls for a more diverse approach that recognizes the interdependence of local processes.

Keywords: forest transition; reforestation; agroforestry; land use change; China

\section{Introduction}

Forests provide numerous crucial ecosystem services to humans, such as the regulation of regional climates, carbon storage and the provision of habitats for flora and fauna. Forests also generate vital income, and they are important for subsistence and for maintaining livelihoods, particularly for the rural poor in developing countries [1,2], including China [3]. Moreover, forested areas are typically found in remote regions where the population density is lower and the incidence of poverty is higher [4]. Changes to forest areas and forest quality can therefore have substantial effects on populations, particularly rural populations grappling with the many challenges associated with remoteness. A better understanding of the causes of changes in forested areas and forest quality is urgently needed to assess the social impacts of these changes and to target development assistance in areas where forest recovery is critical for local livelihoods.

Forest transition theory, which describes the patterns and major driving forces of the shift from net deforestation to net reforestation, has gained particular prominence in understanding historical forest-cover change [5]. An observed shift from deforestation to forest recovery may be linked to multiple and often interacting underlying causes that may result in qualitatively distinct trajectories of change. Rudel et al. [6] compared FAO data on national forest-cover change to define two main "pathways" of forest transitions: forest scarcity and economic development. In the latter, economic growth attracts rural labor to industrial centers, leading to rural labor scarcity, cropland abandonment and eventual reforestation of abandoned fields. The forest scarcity pathway occurs when decreasing availability of forest products spurs price increases in forest products. As a result, incentives for landowners and policy makers to invest in afforestation increase. Lambin and Meyfroidt [7] expanded upon this explanatory framework by adding three pathways and by connecting the resulting five pathways to classify individual cases. First, the authors identified the state forest policy pathway, which captures government investments in forestry for reasons other than forest scarcity. Second, the globalization pathway encompasses the responses of land users to neoliberal market reforms, international migration or tourism in an increasingly interconnected world. Third, the smallholder intensification pathway represents investments in agroforestry systems as a form of land use intensification, which is associated with a change in farming systems that augments the share of tree-based cultivation. Identifying varying catalysts of forest change is useful for developing appropriate policies, and the pathway concept is a useful framework for explaining forest transitions.

The pathway framework also has great heuristic value in linking aggregate forest changes to variable underlying causes. Many empirical investigations have employed these ideas, mainly at the national level $[8,9]$. However, most analyses to date have focused on national or multi-national analyses 
rather than local characteristics $[10,11]$. By reversing the traditional analytical lens, we can examine how local contexts are subjected to a variety of interacting broad-scale processes. Local land users encounter some combination of national policies, institutional changes and market variations; such changes are mediated by local socioecological circumstances and can thus result in a variety of land use responses. For example, forest cover may decline in one region and recover in nearby regions [10], or locally different land-management strategies may result in spatially varying reforestation efforts [11]. Therefore, improved knowledge of the importance of different pathways at the local level, as well as their interactions and contingencies, is important $[8,11]$.

In this study, we use the pathway concept as a typological tool to guide an empirical examination of village-level processes in Yunnan Province, China. The deterioration of forest-based ecosystem services in Yunnan played a pivotal role in the formulation of major state policies in China to increase forest cover [12]. We conducted an investigation of 10 villages in two areas in the province to analyze different pathways of forest-cover change over time. The data stem from the participatory reconstruction of forest-cover changes between 1960 and 2010 and in-depth interviews with key informants in all of the villages. We interpreted forest transition processes at the village level to exemplify how forest transitions can exhibit large variations over time and space. We exploit this variation to demonstrate the differences in the importance of particular drivers, which result in different pathways of reforestation. We also describe how these changes in land use were contingent on the asset endowments and economic opportunities of local land users.

\section{Forest Transition in China}

After periods of extensive timber extraction and clear cutting during the Great Leap Forward in the 1960s and the Cultural Revolution in the 1970s, deforestation slowed, and large-scale afforestation (We use the definition proposed by Watson et al. [13], i.e., reforestation and afforestation are synonymous) programs were initiated by the Chinese government. For example, the Three-North Shelter Forest Program (also known as the Great Green Wall) was initiated in 1978; this program aimed to combat desertification in northern China by increasing forest cover from $5 \%-15 \%[14,15]$. As a result, and arguably as a response to these initiatives, China experienced a national forest transition from a net forest loss to a net forest gain by approximately 1981, according to the seven national forest inventories [16]. However, the turning point in 1981 is debatable because the definition of "forest" and the measurement design and technologies across these inventories were not consistent and because the inventories were only conducted every five to seven years [16,17]. Furthermore, despite the increase in national forest cover, many scholars highlight the deterioration of forest quality and the decline in forest biomass stocks [18-20].

One important reason for the net increase in forest cover after 1981 was the Forestry Reform, which was implemented in 1982. The main goal of the reform was the decentralization of forest management to local communities and individual households under a forestland allocation policy called "Forestry Three Fixes" [21,22]. (The collective forest tenure reform, implemented in 2006, aimed to strengthen these goals by establishing long-term rights for farmers to use and manage community forestry resources [23-25]) More recently, however, forest scarcity became the predominant driver of the increase in forest cover in China [6]. After the Yellow River drought in 1997 and the severe floods of 
the Yangtze River in 1998, the Chinese government implemented a set of forestry policies to address and reverse the degradation of middle and upper watersheds caused by the loss of ecosystem services, such as flood protection and water runoff from forested lands [14].

The most prominent afforestation policies in China are the Natural Forest Protection Program (NFPP) and the Sloping Land Conversion Program (SLCP). The NFPP was first implemented in 1998 and was intended to restore natural forests in the upstream regions of major rivers by banning logging and supporting the reforestation of degraded forests [18]. The SLCP was implemented shortly afterward in 1999 to reduce erosion on sloped croplands through afforestation and reforestation [26]. However, afforestation efforts have often inadequately addressed the high diversity in ecosystems and livelihoods in China and have instead concentrated on fast-growing or economically valuable species (some of which are not widely recognized as forest species, such as rubber) that frequently fail to restore ecosystem functions [19,27,28]. Therefore, "tree-cover transition" is arguably a more accurate term than "forest transition" for the change from net forest loss to net forest gain in China. Nevertheless, for the sake of simplicity, we use the term "forest transition" in this study to describe the observed tree-cover changes.

Upon close examination, the observed forest transitions in China appear to have many interacting causes. Since the 1980s, rampant economic growth has resulted in the largest internal migrations in human history [29,30]. Economic development and migration significantly reduced on-farm labor supply [31] and may have also reduced pressure on forestlands by slowing agricultural expansion. In some mountainous regions, marginal fields were abandoned and reforested [29,30]. As Lambin and Meyfroidt [7] found in Vietnam, the economic importance of trees and tree crops also contributed to an increase in forest cover in China. For example, high commodity prices largely driven by increasing domestic demands led to the massive expansion of rubber plantations [20]. In addition to the export-led economic development concomitant with the implementation of the logging ban in 1998, deforestation and forest degradation within China were increasingly displaced to other countries through rising timber imports [32]. Moreover, the forest transition in China would not have been possible in its present form without substantial timber imports [32,33]. Hence, we suggest that the distinction Lambin and Meyfroidt [7] made between the globalization pathway and the economic development pathway may not be helpful for understanding the situation in China because the two pathways are closely intertwined; i.e., economic growth is intrinsically linked to the export sector.

Moreover, smallholder tree-based intensification, such as rubber plantations in southern Yunnan and the expansion of walnut trees in northwest Yunnan, also led to the increase in tree cover [20,34]. Therefore, ascribing reforestation in China to only one set of factors is problematic. Instead, different but interacting processes are likely simultaneously at play in particular locales.

\section{Material and Methods}

\subsection{Study Site}

Yunnan Province is located in southwestern China, and it borders Myanmar, Laos and Vietnam (Figure 1). The province is situated to the east of the Himalayan Plateau and is dominated by a combination of deep river valleys and steep slopes. The complex terrain results in a range of different 
landscapes and climatic conditions, from tropical forests in the southwest to permanent glaciers on the high mountain peaks in the north. The headwaters of the Yangtze, Salween, Irrawaddy, Mekong, Red and Pearl Rivers are located within this montane province. Because of its diverse landscape and biophysical conditions, Yunnan is widely hailed as a global biodiversity hotspot [35]. Yunnan's forest cover of $47.5 \%$ is far above the national average forest cover of $20.4 \%$ [36]. Abundant forest cover, the importance of forest livelihoods [37] and the recent implementation of major afforestation policies suggest that Yunnan is an ideal location for studying the underlying causes of forest transitions.

Figure 1. Study area.

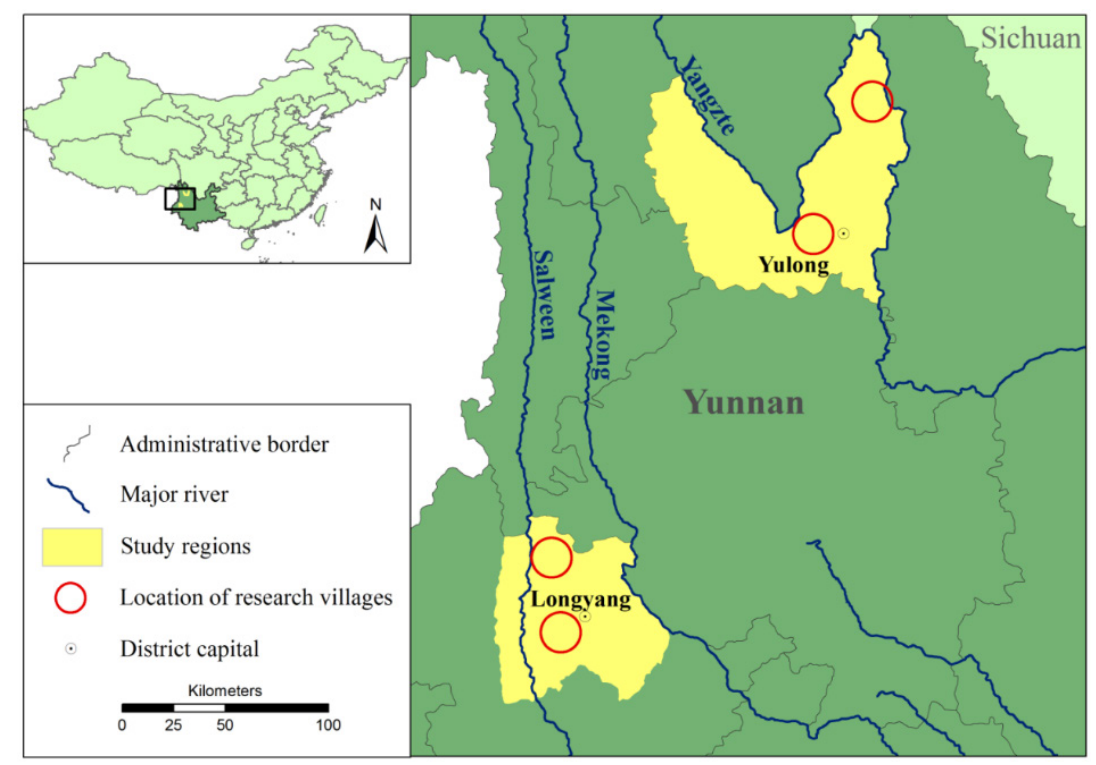

Yunnan is characterized by 25 ethnic minority groups that constitute $38 \%$ of the total population [36]. Land use in the study site is variable: agro-pastoralism is practiced by Tibetans in the highlands; upland agriculture is practiced by the Yi and Han Chinese; and paddy rice is cultivated in the valleys [38]. The majority of the population in Yunnan lives in mountainous rural areas and partly relies on forests for collecting firewood and constructing wood and non-timber forest products [39]. Yunnan is among the poorest provinces in China, with many of its rural poor living in poverty [40,41].

The 10 study villages are located in two distinct regions in Northwest Yunnan: five villages are in Yulong County, and five villages are in Longyang District (Figure 1). Substantial differences in the biophysical conditions characterize the villages in the two regions; nevertheless, they have comparable land-use strategies (Table 1). Agricultural land use in all studied villages is dominated by corn, wheat and paddy rice, which are mainly used for subsistence purposes. Coffee and tea, along with increasingly more common pears and walnuts, are planted as tree crops to generate farm-based income. Capital inputs into agriculture are largely confined to intermediate inputs, such as fertilizer and pesticides, and very few farm households in the study villages use machinery, such as rice threshers or tractors. Most farm work is performed manually; thus, labor is a key production factor. In addition to crop production, animal husbandry, and forestry, seasonal migration is the most important income source for one-quarter of the households in the study villages; however, income levels vary substantially between villages [34]. 
Table 1. Village description.

\begin{tabular}{|c|c|c|c|c|c|c|c|c|c|c|}
\hline \multirow[b]{2}{*}{ Features } & \multicolumn{10}{|c|}{ Villages } \\
\hline & Hong & Huang & Lan & $\mathbf{L u}$ & Cheng & $\mathbf{Z i}$ & Qing & He & Hei & Bai \\
\hline Prefecture & Yulong & Yulong & Yulong & Longyang & Longyang & Yulong & Longyang & Longyang & Yulong & Longyang \\
\hline $\begin{array}{l}\text { Travel time to } \\
\text { market (hours) }\end{array}$ & 2 & $<1$ & 6 & 2 & 7 & 8 & 8 & 7 & 3 & 2 \\
\hline Topography & Medium & Gentle & $\begin{array}{c}\text { Rough } \\
\text { (terraces) }\end{array}$ & Medium & Medium & $\begin{array}{c}\text { Rough } \\
\text { (terraces) }\end{array}$ & Medium & Medium & Rough & Medium \\
\hline Harvests/year & 2 & 1 & 2 & 2 & 2 & 2 & 2 & 2 & $1-2$ & 2 \\
\hline Subsistence crops & $\begin{array}{l}\text { Corn } \\
\text { Wheat } \\
\text { Rice }\end{array}$ & $\begin{array}{l}\text { Wheat } \\
\text { Beans } \\
\text { Barley }\end{array}$ & $\begin{array}{l}\text { Corn } \\
\text { Wheat } \\
\text { Rice }\end{array}$ & $\begin{array}{c}\text { Corn } \\
\text { Wheat } \\
\text { Rice }\end{array}$ & Corn & $\begin{array}{c}\text { Corn } \\
\text { Wheat } \\
\text { Rice }\end{array}$ & Corn & $\begin{array}{l}\text { Corn } \\
\text { Rice }\end{array}$ & $\begin{array}{c}\text { Potato } \\
\text { Buckwheat }\end{array}$ & $\begin{array}{c}\text { Corn } \\
\text { Wheat } \\
\text { Rice }\end{array}$ \\
\hline Cash crops & None & None & $\begin{array}{l}\text { Sichuan } \\
\text { pepper }\end{array}$ & None & $\begin{array}{c}\text { Tobacco } \\
\text { Medical herbs } \\
\text { Safflower }\end{array}$ & None & Sugar cane & $\begin{array}{c}\text { Tobacco } \\
\text { Medical } \\
\text { herbs }\end{array}$ & Rapeseed & $\begin{array}{l}\text { Sichuan } \\
\text { pepper }\end{array}$ \\
\hline Cash trees & $\begin{array}{l}\text { Apple } \\
\text { Peach } \\
\text { Walnut }\end{array}$ & Apple Peach & $\begin{array}{c}\text { Pear } \\
\text { Walnut }\end{array}$ & $\begin{array}{l}\text { Pear Tea } \\
\text { Walnut }\end{array}$ & Walnut & Walnut & $\begin{array}{c}\text { Eucalyptus } \\
\text { Tea } \\
\text { Walnut }\end{array}$ & Walnut & $\begin{array}{c}\text { Apple } \\
\text { Peach } \\
\text { Sichuan } \\
\text { pepper }\end{array}$ & $\begin{array}{c}\text { Pear } \\
\text { Walnut }\end{array}$ \\
\hline SLCP & Yes & No & Yes & Yes & Yes & Yes & No & Yes & Yes & Yes \\
\hline Income level & Medium & High & Low & Medium & Medium & Medium & Low & Low & Very low & Medium \\
\hline $\begin{array}{c}\text { Non-farm income } \\
\text { sources }\end{array}$ & $\begin{array}{c}\text { Migratio } \\
\mathrm{n}\end{array}$ & Tourism & Migration & Negligible & Migration & Tourism & Negligible & Negligible & Migration & Migration \\
\hline $\begin{array}{c}\text { Approximate } \\
\text { village area }\end{array}$ & $6 \mathrm{~km}^{2}$ & $1.6 \mathrm{~km}^{2}$ & $1.8 \mathrm{~km}^{2}$ & $1.4 \mathrm{~km}^{2}$ & $5.4 \mathrm{~km}^{2}$ & $3 \mathrm{~km}^{2}$ & $1.4 \mathrm{~km}^{2}$ & $6.9 \mathrm{~km}^{2}$ & $4.5 \mathrm{~km}^{2}$ & $3 \mathrm{~km}^{2}$ \\
\hline
\end{tabular}


In each county, we selected two groups of villages based on the travel times to the nearest major market because expert interviews and a literature review suggested that market access crucially shapes land-use strategies, the state of forests and income levels in the study area. Proximity to markets reduces transportation costs and maintains the quality of perishable products, such as fruits, which affect crop choices in the study area. Market access also increases commuting distance and affects employment opportunities in urban areas, such as in the construction or service sector $[42,43]$.

Within each region, half of the selected villages are therefore located within three hours (by bus) of the county capitals, while the other villages are situated in more remote settings that are five to eight hours away from the county capitals (Table 1) [34].

\subsection{Data Collection}

We used several participatory methods to understand how the catalysts for the forest transitions vary in different locales and between actors. We facilitated group discussions with a broad range of up to 15 actors in each village. In all discussions, we used identical qualitative-data elicitation techniques. The participants in the group discussions were chosen at random from different age groups, genders and income strata to represent a cross-section of the village population. We began the group discussions with participatory mapping from plots of high-resolution satellite images (Quickbird, IKONOS, and WorldView) to derive current forest-cover maps for the entire village territory [44]. Villagers mapped current (2010) land use on the plots and the main changes in land use since the 1950s. The land-use maps provided an overview of village-level land use and supported the subsequent group discussions.

In the next step, we asked villagers to estimate the trends of forest-cover change from the period before the start of the Great Leap Forward in 1958 until 2010. The following classes of forest cover were defined by the villagers:

(1) Primary, largely undisturbed forest (virtually absent and subsequently ignored);

(2) Secondary forests that contain naturally regrown forests;

(3) Plantation forests that encompass all tree plantings, either pure tree plantations or agro-forest systems; and

(4) Total forest that comprises all of the above forested land

We then reconstructed past changes in each of the forest-cover classes in each village since the 1950s. Participants estimated the percent of forest cover during landmark events relative to the baseline extent of forest cover in the reference year of 2010. The landmark events encompass benchmark episodes that participants remembered, such as the Great Leap Forward in the late 1950s, the year the household responsibility system (HRS) was introduced and the years major state forest policies (SLCP and NFPP) were implemented in the village. We then connected the point estimates and used the resulting curves to discuss forest-cover changes with participants. We repeated these steps for all forest-cover categories to obtain relative forest-cover changes. To triangulate the results, we repeatedly referred to the participatory maps, extensively discussed the changes, and facilitated discussions among participants with the aim of attaining a consensus among the villagers. As a result, we obtained qualitative reconstructions of the forest transition curves between 1958 and 2010 for each 
village. We used these village-level forest transition curves to infer local-level differences in patterns and processes of forest-cover change, such as the rate of change, the time of the transition and the speed of forest recovery. Such long-term data spanning 50 years are not otherwise available because satellite images at sufficient resolutions have only been captured since the mid-1980s; other spatial data are either unavailable or inaccessible in China.

We used the village-level forest-transition curves and the participatory land-use maps as tools to facilitate discussions with the participants about the proximate causes and underlying drivers of the identified changes in forest cover. These discussions were particularly useful for obtaining an in-depth understanding of how and why land use and forest cover changed, how villagers make land-use decisions and which factors influence these decisions. We constructed concept maps [47] with the village stakeholders to structure the outcomes of the group discussions (Figure 2). Concept maps help to derive the causes and effects of land-use changes in a flexible and simple way while generating valuable information on the perception of land-use changes. These concept maps visually illustrate the linkages between causal variables that influence land-use decisions and reveal the importance of individual variables (Figure 2). These maps allowed us to extract the overarching causal influences on land-use and forest-cover changes that are contingent on specific local circumstances and changes in external conditions.

Figure 2. Example of the concept map for the village of $\mathrm{Zi}$ based on the group discussions.

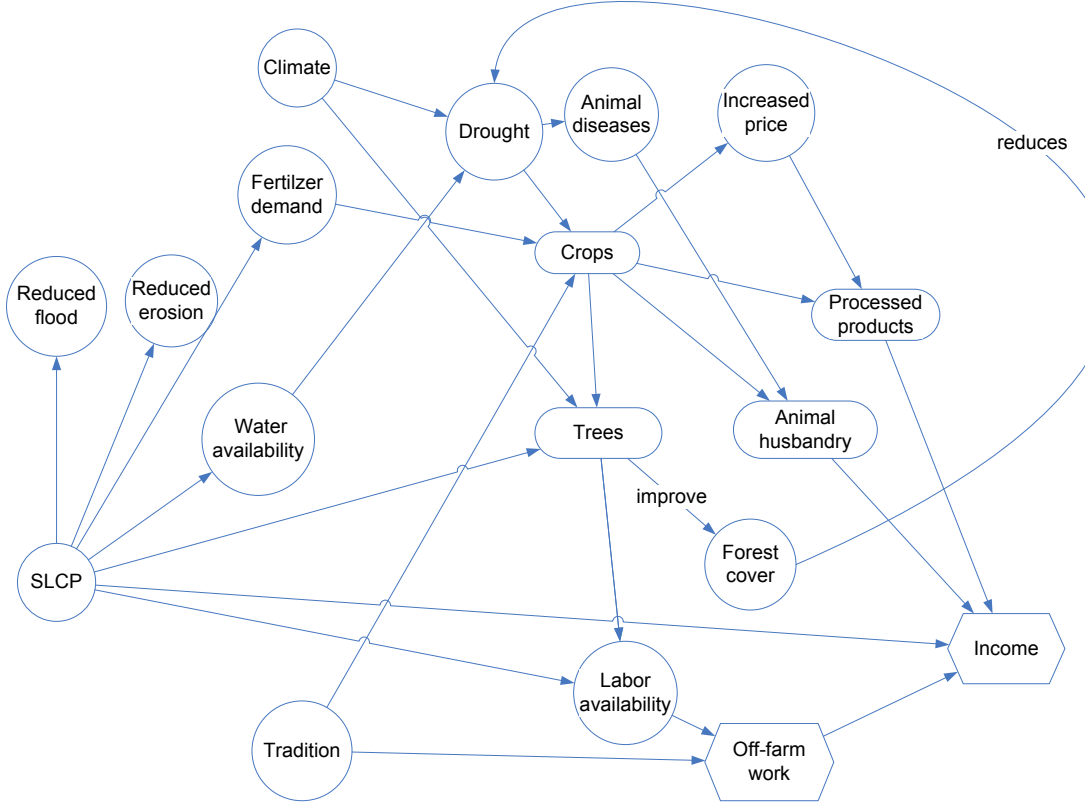

Combining the qualitative assessments of the forest-cover changes and the in-depth group discussions in all of the villages allowed us to compare the patterns and causes of forest-cover changes across the villages over time. We used this knowledge to discuss the importance of particular processes, to compare the patterns of forest-cover change in each village and to assess the spatial and temporal variations in the effects of the driving forces of forest-cover change. Using the main drivers identified in the concept mapping exercise, we classified each village by the dominant drivers of land-use change into the appropriate pathway concept (Table 1). For instance, we classified the forest scarcity pathway as the dominant cause of forest transition when the primary cause of the forest-cover increase 
was the implementation of the SLCP by state authorities, i.e., the government response to flooding and reduced water availability perceived as the result of upstream forest clearing. In other words, we qualitatively assessed individual drivers in the concept maps and conceptually associated the drivers with the particular pathway that was most closely related.

\section{Results}

The relative changes in the forest cover of secondary forests, plantation forests and total forests are depicted in Figure 3 for each village and as the mean for all the villages (bottom right of Figure 3 ). The changes in the forest-cover categories exhibit some remarkable similarities across villages, despite substantial differences in the villages' biophysical and socioeconomic characteristics ( $c f$. Table 1). All the villages have more forests today than in 1958, and forest-cover has increased across all the villages since 1990. In all but one village (Qing), we observed a forest transition between 1980 and 2000. Qing had its lowest total forest cover before the onset of the Cultural Revolution in 1966 (at which point it had approximately one quarter of its 2010 forest cover), and it has experienced continually increasing total forest cover since 1966. In several villages, the total forest cover remained relatively stable after the Great Leap Forward in 1958 but increased rapidly during the 1990s. The secondary forest cover has increased in most villages since the 1980s, yet it is still below the 1960s level in four villages. The mean low point of the total forest cover in all the villages occurred in 1985, when the total forest cover accounted for just over half (55\%) of the forest cover in 2010 (bottom right panel of Figure 3). This finding corresponds fairly well to the reported timing of the forest transition across Yunnan Province between the mid-1980s and the early 1990s [38,45].

The most striking and synchronous change was the emergence of plantation forests in all the villages beginning in approximately 1980. The growth of afforested and reforested areas coincided with the implementation of the Household Responsibility System in 1979 and with the forestland reform in 1982 [21]. The expansion of plantation forests greatly accelerated after 1999, along with the progressive implementation of the SLCP in Yunnan (Figure 3).

Figure 4 clearly demonstrates the swift emergence of plantation forests, particularly since the onset of the SLCP. The mean area of plantation forestry has more than doubled since 2003. Between-village variation is small, and villages that did not participate in the SLCP also experienced considerable increases in plantation forest without compensation. Villagers expect a further increase in plantation forests by $10 \%$ between 2010 and 2020 (Figure 4).

Figure 3 shows that the villages have exhibited similar forest-cover changes since 1960. However, the underlying reasons for the changes fundamentally differ. Six of the 10 villages (Lu, Bai, Hei, Hong, $\mathrm{Zi}$ and Lan) are characterized by land-use systems that rely on corn as fodder for raising pigs (Table 1). Agricultural production mainly focused on addressing subsistence needs in these villages. Off-farm job opportunities led to the long-term migration of younger household members and the short-term or seasonal migration of male household heads. Migration increasingly generated income for these households and contributed to improved household welfare but a lower supply of agricultural labor. In the villages with higher levels of migration, the SLCP was initially the most conspicuous reason for expanding tree cover on former croplands. Tree crops were often seen as economically favorable compared with traditional agricultural crops because they had lower labor demand, they 
were compensated by the SLCP and they generated sizeable income through the sale of tree crops. Other government programs, such as the walnut program that provided support for walnut tree planting [12], also contributed to the increase in tree cover. Walnuts are particularly promising because they can easily be stored, and the growing demand for walnuts has significantly increased their value. Walnut tree plantations have lower labor requirements than crop and livestock farming, with a single labor peak during the harvesting season [46]. The success of early adopters of walnut trees motivated other farmers to plant walnuts and, to a lesser extent, other fruit trees, such as peaches and apples, on their own initiative without government compensation [34,44]. Although planted tree crops in these villages were initially compensated by the SLCP and the walnut program, tree crops were increasingly considered economically favorable compared with traditional agricultural crops because they have a lower labor demand and generate a sizeable income through crop sales.

Figure 3. Historical forest-cover change at the village level (relative changes using 2010 as the reference year, for which all forest-cover categories were normalized to 100; see Section 3.2 for an explanation of the data collection).

Bai

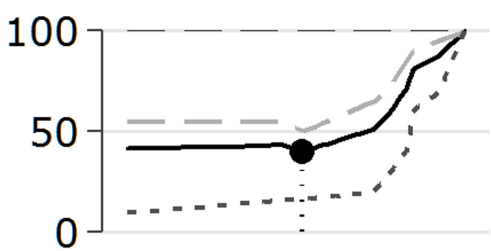

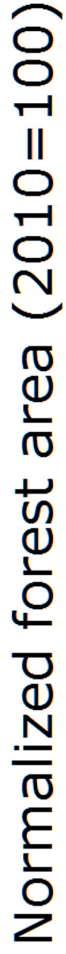

\section{Cheng}

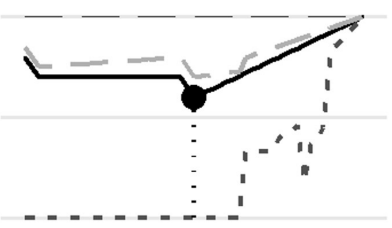

Hei

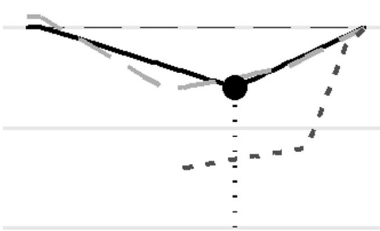

Lan

$\mathrm{Zi}$

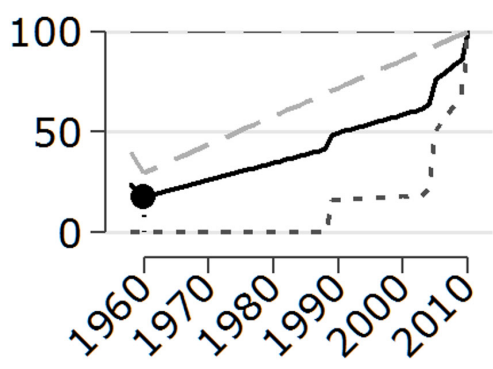

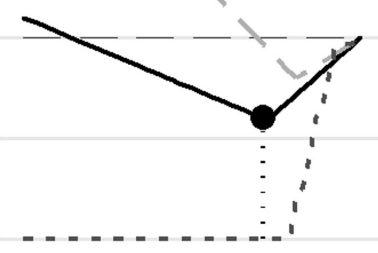

- Total forest

- - Secondary forest

Plantation forest

Low point

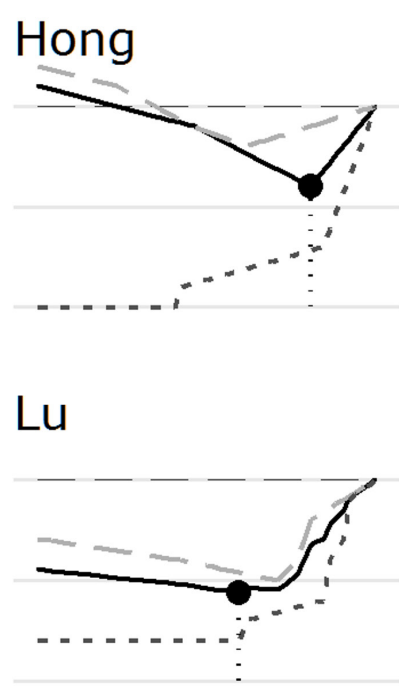

Mean change
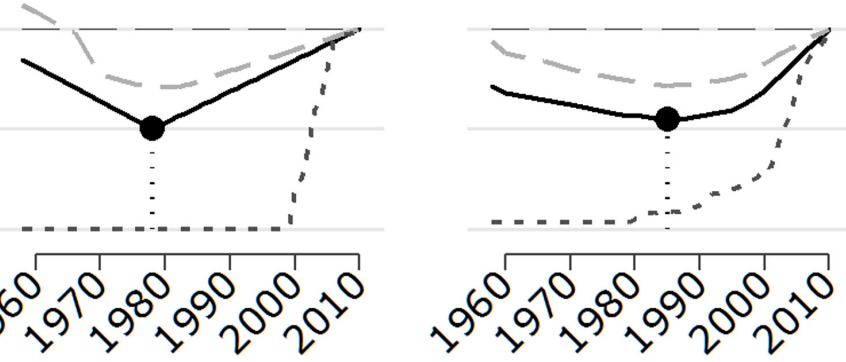
Figure 4. Emergence of plantation forests.

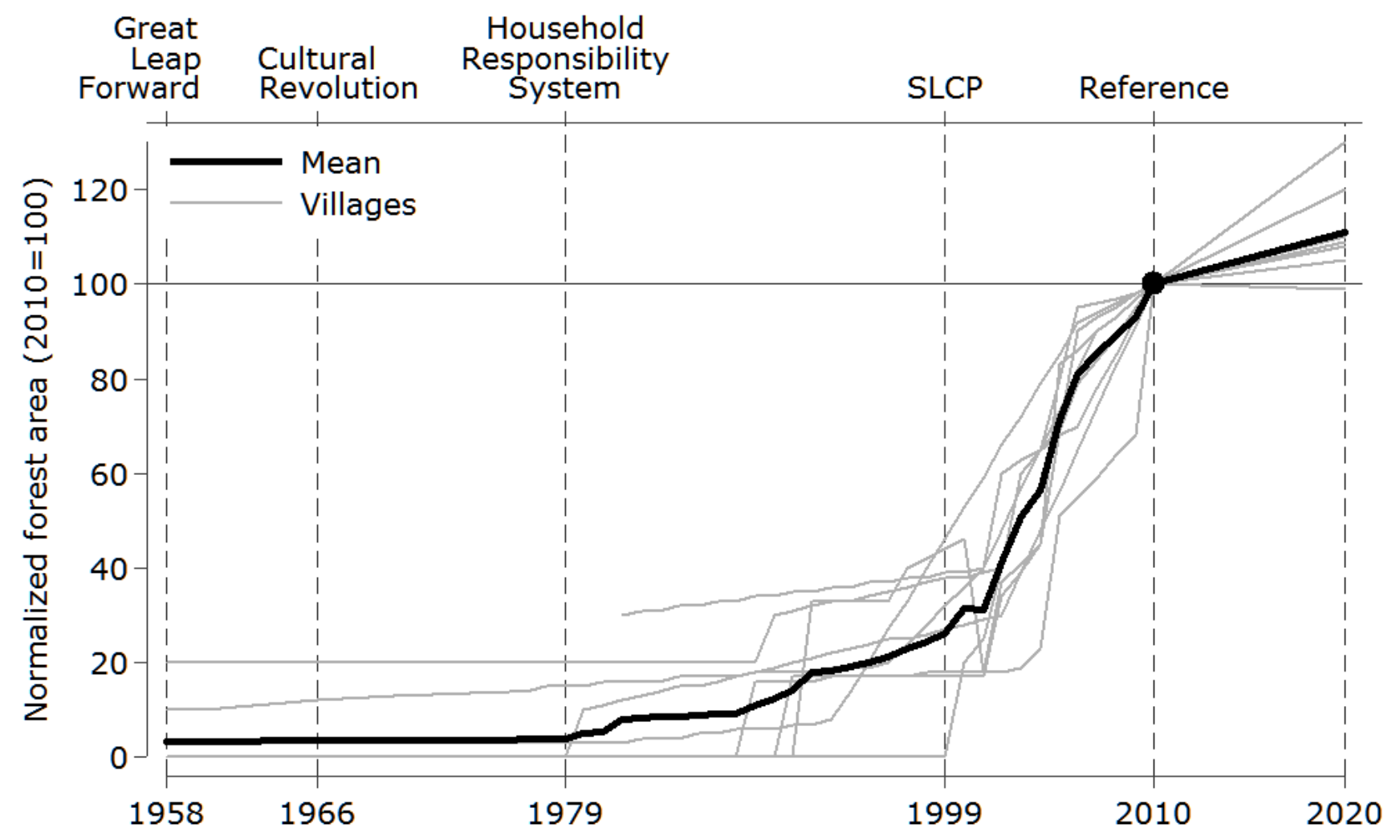

The villages of He and Cheng also participated in the SLCP. However, the SLCP subsidies and income from tree crops were only minor income sources in these two villages, where farmers reported higher profits from annual cash cropping. In Cheng, farmers cultivated safflower (Carthamus tinctorius) as a cash crop because the natural conditions in Cheng favor safflower cultivation and result in good harvests and high profits. The villagers of He obtained a state-guaranteed quota with fixed compensation for tobacco cultivation, which represents a stable income source. The high profits resulting from alternative land uses in He and Cheng outweighed the payments from the SLCP and the potential return from tree crops; both villages therefore experienced little reforestation (Figure 3).

Finally, two villages in our sample (Huang and Qing) did not receive an SLCP quota, but farmers in the two villages still converted significant areas from cropland to trees. Huang witnessed a shift from horticulture to agroforestry on a large portion of its land because a local water protection program and changes in the rights to use surface water from the surrounding mountains caused water shortages that affected agricultural production in the early 1990s. As a result, farm households increasingly invested in agroforestry systems that combined fruit trees with annual crops to use scarce water more efficiently. In Qing, households converted cropland to trees in anticipation of SLCP subsidies. However, to the surprise of the villagers, they never received the subsidies because the village was not targeted by the program, despite the promises of the local authorities. Nevertheless, tree plantations are expanding in Qing without government compensation. Therefore, in both Qing and Huang, households privately invested in tree crops. In both villages, households also indicated a strong desire to continue investing in agroforestry and to expand the areas with cash trees in the future. 


\section{Discussion}

The results show that aggregate forest-cover changes are surprisingly similar in terms of relative change and temporal evolution, despite the substantial differences in land-use strategies, socioeconomic status and cultural backgrounds. Therefore, the overall trend of forest-cover change is conditioned by high-level political and economic conditions that affect local forest-cover changes in a similar manner. However, we observe considerable local differences in the pathways to the forest transition at the village level. In other words, local land users react to external underlying drivers in very distinct ways, contingent on socioeconomic, demographic and biophysical conditions. Therefore, the underlying processes of the forest transition differ substantially among villages. This study suggests that characterizing case studies based on aggregate forest changes may obscure critical local-level variations.

Our findings underscore the importance of the state in forest-cover increases until approximately 2000, largely due to the state-forest enterprises that essentially pursued commercial forestry for timber production $[47,48]$. Although the state continued to play a central role in the management of state and community forests, the importance of forests as economic resources for the state gradually decreased. This decline can mainly be attributed to the logging ban that was imposed by the NFPP and enacted in 1998 and the associated harvest reduction in state-forest land [49].

The forest scarcity pathway became the dominant driver of forest-cover changes from the late 1990s, when the escalating scarcity of forest products and forest ecosystem services spurred the implementation of the logging ban and the SLCP. The importance of these government programs in terms of land area and the number of farmers affected has declined in our study area since the mid-2000s, and their impact on afforestation has become less pronounced. Along with the monetary incentives from the SLCP, the increasing demand for tree crops and improved market conditions led to a considerable reorganization of land use toward agroforestry and the planting of trees crops by rural households [cf. 34]).

The rising importance of the pathway of smallholder intensification emerged toward the end of our study period as a major process that significantly contributed to increasing forest cover. Smallholder intensification in the study villages was mainly dominated by tree-based cash cropping, such as walnut and fruit tree plantations that were established on former croplands. The emerging dominance of smallholder intensification for forest-cover increases was crucially tied to the SLCP, which incentivized the conversion of marginal plots to agroforestry. Farmers who did not want to participate in the SLCP or who could not participate in the SLCP frequently followed their peers in planting tree crops once the economic benefits became apparent [cf. 46]. Agroforestry systems thus emerged as a key response of land users to the economic incentives provided by tree crops. We argue that the forest transition in our study sites is partly an effect of the response of smallholders to emerging economic opportunities in tree cropping. However, "tree-cover transition" may be a better label for the dynamics that we observed locally because most of the increase in "forests" can be attributed to the planting of cash trees that may not qualify for many of the existing definitions of a "forest". Cash trees provide ample economic benefits for local land users, but the increase in non-provisioning forest ecosystem services and the regional and global environmental benefits associated with the tree cover increase are limited. 
Mather and Needle [50] described forest transition as a land-use adjustment based on land rent in the style of von Thünen, in which agriculture is concentrated in the most suitable areas. In our case, the land-use adaptations are the result of adjustments to available rural labor resources. The contraction of the rural labor force was a consequence of the broader socioeconomic developments in China, where the gap in living standards between rural and urban areas has continuously increased since the late 1980s $[42,43]$. Economic development in urbanizing areas fostered massive emigrations from rural areas and reduced rural surplus labor [31]. In addition, population control policies, albeit slightly eased in rural areas, further reduced the rural labor pool [51]. Tree-based cultivation balances labor constraints that are induced by the temporary or permanent emigration of younger family members and the aging rural population [34] and thus represents a rational economic response to a lower labor supply.

In summary, the increase in forest cover since 1990 has been driven by diverse and interactive factors at the local scale. Different pathways to the forest transition co-occur, and their influence over time is contingent on how broadly the economic and political drivers influence the responses of local land users. These processes can also be observed in other areas of China. Both the policy response to forest scarcity and broader economic developments occurred throughout the country [52].

\section{Conclusions}

Prior research on forest transitions has emphasized the need to situate case studies on forest transitions within broader comparative frameworks [7]. Thus, we used a heuristic concept of forest transition pathways to determine how 10 villages in Yunnan Province, southwestern China, were affected by multiple, interacting processes that shape long-term forest-cover change. Using qualitative information obtained from participatory data elicitation approaches, we reconstructed village-level forest transition curves and demonstrated how national policy and smallholder responses to changing economic conditions shaped local land use and forest transitions in our study villages. Local forest transitions are contingent on the interactions of many factors, and they exhibit path dependency.

The results demonstrate the importance of state policies as a key driver of forest-cover increases after periods of forest scarcity. Particularly in China, these changes are considered to be driven by state policies [9]. Indeed, the scope and speed of these directly targeted environmental policy reforms are arguably unprecedented. However, the Yunnan case illustrates how the impact of state policies is influenced by other contextual factors that often unfold over time. Recently, improved economic opportunities and the changing relative availability of agricultural production factors, particularly the rural labor scarcity induced by migration and low birth rates, motivated smallholders to implement major land-use adjustments. Farmers increasingly shifted away from traditional production modes and opted to plant trees on former croplands; this decision had numerous consequences for landscapes and the rural economy. Land-use systems became increasingly commercialized, and agricultural income tended to increase with tree-based production. However, the effects observed in our study villages are quite different from the standard economic development pathway, which stresses that migration causes rural labor shortages and reforestation on abandoned croplands. In our study villages, only small amounts of cropland were abandoned; farmers substituted capital-intensive production for 
labor-intensive production while maintaining constant land inputs to maximize the economic return of the scarcest factor of production (i.e., labor).

Farmers continue to cultivate their marginal plots to maintain their land-use rights because abandonment may result in the reallocation of the land-use rights to other villagers $[51,53]$. In addition, tree-based cultivation increases the variety of crops and income sources, income security, local dietary diversity and food security of farm households [54]. This outcome is particularly appealing to the small, aged households in our study area that lack economically successful migrants in the family.

The regime shift in the orientation of farming systems toward agroforestry was triggered by state programs that responded to the escalating scarcity of forest ecosystem services and was fueled by economic development in other sectors. However, a uni-directional, static explanation of forest transitions may confound conclusions and neglect the large local variability. Therefore, the various combinations and interrelationships of explanatory processes, the shifts in driving forces over time and the associated spatial variations should be emphasized. Our insights derived from local case studies are important for refining forest transition theory by emphasizing the contingency and path dependency of forest transition pathways.

\section{Acknowledgments}

We gratefully acknowledge the financial support of the Joint Science Conference (GWK) under the "Pakt für Forschung und Innovation" (PAKT) for the IAMO International Research Group "Economic Dynamics and Social Equilibrium in Rural China". We also acknowledge the financial support of the research project entitled "Impacts of Reducing Emissions from Deforestation and Forest Degradation and Enhancing Carbon Stocks (I-REDD+)", funded by the European Commission's Seventh Framework Research Programme. Special thanks are given to Caizhen Lu and Yufang Su at the Center for Mountain Ecosystem Studies, Kunming, China. Additionally, the comments of the three anonymous reviewers helped improve the manuscript.

\section{Author Contributions}

Jens Frayer, Daniel Müller and Zhanli Sun designed research. Jens Frayer, Daniel Müller and Zhanli Sun collected and analyzed the data. Jens Frayer, Daniel Müller and Zhanli Sun, Darla K. Munroe and Jianchu Xu performed research and wrote the paper.

\section{Conflicts of Interest}

The authors declare no conflict of interest.

\section{References}

1. Vedeld, P.; Angelsen, A.; Sjaastad, E.; Berg, G.K. Counting on the Environment: Forest Incomes and the Rural Poor; The World Bank: Washington, DC, USA, 2004.

2. Sunderlin, W.D.; Angelsen, A.; Belcher, B.; Burgers, P.; Nasi, R.; Santoso, L.; Wunder, S. Livelihoods, forests, and conservation in developing countries: An overview. World Dev. 2005, 33, $1383-1402$. 
3. Hogarth, N.J.; Belcher, B.; Campbell, B.; Stacey, N. The Role of Forest-Related Income in Household Economies and Rural Livelihoods in the Border-Region of Southern China. World Dev. 2013, 43, 111-123.

4. Sunderlin, W.D.; Dewi, S.; Puntodewo, A.; Müller, D.; Angelsen, A.; Epprecht, M. Why Forests Are Important for Global Poverty Alleviation: A Spatial Explanation. Ecol. Soc. 2008, 13, 24.

5. Mather, A.S. The forest transition. Area 1992, 24, 367-379.

6. Rudel, T.K.; Coomes, O.T.; Moran, E.; Achard, F.; Angelsen, A.; Xu, J.; Lambin, E. Forest transitions: Towards a global understanding of land use change. Glob. Environ. Chang. 2005, 15, 23-31.

7. Lambin, E.F.; Meyfroidt, P. Land use transitions: Socio-ecological feedback versus socio-economic change. Land Use Policy 2010, 27, 108-118.

8. Farley, K.A. Pathways to forest transition: Local case studies from the Ecuadorian Andes. J. Lat. Am. Geogr. 2010, 9, 7-26.

9. Mather, A.S. Recent Asian forest transitions in relation to forest-transition theory. Int. For. Rev. 2007, 9, 491-502.

10. Perz, S.G. Grand Theory and Context-Specificity in the Study of Forest Dynamics: Forest Transition Theory and Other Directions. J. Long Form Workform 2007, 59, 105-114.

11. Klooster, D. Forest transitions in Mexico: Institutions and forests in a globalized countryside. Prof. Geogr. 2003, 55, 227-237.

12. He, J.; Lang, R.; Xu, J. Local Dynamics Driving Forest Transition: Insights from Upland Villages in Southwest China. Forests 2014, 5, 214-233.

13. Watson, R.T.; Noble, I.R.; Bolin, B.; Ravindranath, N.; Verardo, D.J.; Dokken, D.J. Land Use, Land-Use Change and Forestry: A Special Report Of the Intergovernmental Panel on Climate Change; Cambridge University Press: Cambridge, UK, 2000.

14. Xu, J.; Yin, R.; Li, Z.; Liu, C. China's ecological rehabilitation: Unprecedented efforts, dramatic impacts, and requisite policies. Ecol. Econ. 2006, 57, 595-607.

15. Wang, X.; Zhang, C.; Hasi, E.; Dong, Z. Has the Three Norths Forest Shelterbelt Program solved the desertification and dust storm problems in arid and semiarid China? J. Arid Environ. 2010, 74, 13-22.

16. Zhang, Y.; Song, C. Impacts of afforestation, deforestation, and reforestation on forest cover in China from 1949 to 2003. J. For. 2006, 104, 383-387.

17. Song, C.; Zhang, Y. Forest Cover in China from 1949 to 2006. In Reforesting Landscapes; Nagendra, H., Southworth, J., Eds.; Springer: Dordrecht, The Netherlands, 2010.

18. Yin, R.; Yin, G. China's Primary Programs of Terrestrial Ecosystem Restoration: Initiation, Implementation, and Challenges. Environ. Manag. 2010, 45, 429-441.

19. Xu, J. Chinas new forests aren't as green as they seem. Nature 2011, 477, 371.

20. Ziegler, A.D.; Fox, J.M.; Xu, J. The rubber juggernaut. Science 2009, 324, 1024-1025.

21. Xu, J.; Ribot, J.C. Decentralization and accountability in forest management: A case from Yunnan, southwest China. Eur. J. Dev. Res. 2004, 14, 153-173.

22. Liu, D. Tenure and management of non-state forests in China since 1950: A historical review. Environ. Hist. 2001, 239-263. 
23. Xu, J.; Jiang, X. Collective forest tenure reform in China: Outcomes and implications. In World Bank Conference on Land Governance, Proceedings of the World Bank Conference on Land Governance, Washington, DC, USA, 9-10 March 2009.

24. Hyde, W.F.; Belcher, B.; Xu, J. China's Forests : Global Lessons from Market Reforms; Resources for the Future/Center for International Forestry Research: Washington, DC, USA, 2003.

25. Yin, R.; Xu, J.; Li, Z. Building institutions for markets: Experiences and lessons from China's rural forest sector. Environ. Dev. Sustain. 2003, 5, 333-351.

26. Xu, Z.; Bennett, M.T.; Tao, R.; Xu, J. Chinas sloping land conversion programme four years on: Current situation, pending issues. Int. For. Rev. 2004, 6, 317-326.

27. Zhai, D.-L.; Xu, J.-C.; Dai, Z.-C.; Cannon, C.H.; Grumbine, R. Increasing tree cover while losing diverse natural forests in tropical Hainan, China. Reg. Environ. Chang. 2014, 14, 611-621.

28. Putz, F.E.; Redford, K.H. The Importance of defining "forest": Tropical forest degradation, deforestation, long-term phase shifts, and further transitions. Biotropica 2010, 42, 10-20.

29. Ellis, E.; Neerchal, N.; Peng, K.; Xiao, H.; Wang, H.; Zhuang, Y.; Li, S.; Wu, J.; Jiao, J.; Ouyang, H.; et al. Estimating long-term changes in China's village landscapes. Ecosystems 2009, 12, 279-297.

30. Yan, H.; Liu, J.; Huang, H.Q.; Tao, B.; Cao, M. Assessing the consequence of land use change on agricultural productivity in China. Global Planet. Chang. 2009, 67, 13-19.

31. Wang, X.; Huang, J.; Zhang, L.; Rozelle, S. The rise of migration and the fall of self employment in rural China's labor market. China Econ. Rev. 2011, 22, 573-584.

32. Mayer, A.L.; Kauppi, P.E.; Angelstam, P.K.; Zhang, Y.; Tikka, P.M. Importing timber, exporting ecological impact. Science 2005, 308, 359-360.

33. Laurance, W.F. The need to cut China's illegal timber imports. Science 2008, 319, 1184-1185.

34. Frayer, J.; Sun, Z.; Müller, D.; Munroe, D.K.; Xu, J. Analyzing the drivers of tree planting in Yunnan, China, with Bayesian networks. Land Use Policy 2014, 36, 248-258.

35. Conservation International. Mountains of Southwest China. Available online: http://www.conservation.org/where/priority_areas/hotspots/asia-pacific/Mountains-of-SouthwestChina/Pages/default.aspx (accessed on 15 February 2012).

36. China Statistical Bureau. China Statistical Yearbook; China Statistical Press: Beijing, China, 2010.

37. Su, Y.; Li, Q.; Fu, Y. Diversified Livelihoods in Changing Socio-Ecological Systems of Yunnan Province, China; ICIMOD: Kathmandu, Nepal, 2009; pp. 1-37.

38. Xu, J.; Yang, Y.; Fox, J.; Xuefei, Y. Forest transition, its causes and environmental consequences: Empirical evidence from Yunnan of southwest China. Trop. Ecol. 2007, 48, 137-150.

39. Xu, J.; Wilkes, A. Biodiversity impact analysis in northwest Yunnan, southwest China. Biodivers. Conserv. 2004, 13, 959-983.

40. Lu, C. Who is poor in China? A comparison of alternative approaches to poverty assessment in rural Yunnan. J. Peasant Stud. 2010, 37, 407-428.

41. Glauben, T.; Herzfeld, T.; Rozelle, S.; Wang, X. Persistent Poverty in Rural China: Where, Why, and How to Escape? World Dev. 2012, 40, 784-795.

42. Du, Y.; Park, A.; Wang, S. Migration and rural poverty in China. J. Compar. Econ. 2005, 33, 688-709. 
43. Zhao, Y. Labor Migration and Earnings Differences: The Case of Rural China. Econ. Dev. Cult. Chang. 1999, 47, 767-782.

44. Sun, Z.; Müller, D. A framework for modeling payments for ecosystem services with agent-based models, Bayesian belief networks and opinion dynamics models. Environ. Model. Softw. 2013, 45, 15-28.

45. Zhang, Y. Deforestation and forest transition: Theory and evidence in China. In World Forests from Deforestation to Transition? Palo, M., Vanhanen, H., Eds.; Kluwer Academic Publishers: Dordrecht, The Netherlands, 2000.

46. Ediger, L. Economic Integration and Rural Transformation: State-Driven Afforestation in Yunnan, China and the Implications for Landscapes and Livelihoods. Ph.D. Thesis, University of Georgia, Athens, GA, USA, 2006.

47. Zhang, P.; Shao, G.; Zhao, G.; le Master, D.C.; Parker, G.R.; Dunning, J.B.; Li, Q. China's forest policy for the 21st century. Science 2000, 288, 2135-2136.

48. Richardson, S.D. Forests and Forestry in China: Changing Patterns of Resource Development; Island Press: Washington, DC, USA, 1990.

49. Yin, R.; Xu, J.; Li, Z.; Liu, C. China's Ecological Rehabilitation: The Unprecedented Efforts and Dramatic Impacts of Reforestation and Slope Protection in Western China. China Environ. Ser. 2005, 7, 17-32.

50. Mather, A.S.; Needle, C.L. The forest transition: A theoretical basis. Area 1998, 30, 117-124.

51. Knight, J.; Deng, Q.; Li, S. The puzzle of migrant labour shortage and rural labour surplus in China. China Eco. Rev. 2011, 22, 585-600.

52. Perez, R.M.; Belcher, B.; Fu, M.; Yang, X. Looking through the bamboo curtain: An analysis of the changing role of forest and farm income in rural livelihoods in China. Int. For. Rev. 2004, 6, 306-317.

53. Wang, H.; Tong, J.; Su, F.; Wei, G.; Tao, R. To reallocate or not: Reconsidering the dilemma in China's agricultural land tenure policy. Land Use Policy 2011, 28, 805-814.

54. Van Noordwijk, M.; Bizard, V.; Wangpakapattanawong, P.; Tata, H.L.; Villamor, G.B.; Leimona, B. Tree cover transitions and food security in Southeast Asia. Global Food Secur. 2014, 3, 200-208.

(C) 2014 by the authors; licensee MDPI, Basel, Switzerland. This article is an open access article distributed under the terms and conditions of the Creative Commons Attribution license (http://creativecommons.org/licenses/by/4.0/). 